\title{
PENGELOLAAN KEUANGAN IBU VS KELUARGA BAHAGIA
}

\author{
Nina Woelan Soebroto \\ Jurusan Akuntansi, Politeknik Negeri Semarang, Jl. Prof. Soedarto, S.H., Tembalang, \\ Semarang 50275 \\ woelansoebrotonina@gmail.com
}

\begin{abstract}
The family is a reflection of a country. Happy or not a family is burdened on a mother, regardless of their family background or where they come from. Finance is an important thing to support the fulfillment of primary/secondary needs. Unavailability of money when needed can lead to family problems, and family members become depressed.

This service activity aims to help mothers manage their family finances, so that family peace can be created. The implementation of the activity was preceded by socialization to the mothers at the RT,RW,Dawis and PKB meetings.

The activity began with a presentation on family financial management, procedures for opening savings at BMT Polidana Polines, followed by sharing about financial problems in the family, as well as assistance to increase understanding of the importance of financial management. Motivation is by providing a subsidy of IDR12,000 for each account opening (principal savings of IDR10,000 and mandatory savings of IDR2,000).

Subsidies can attract residents to start saving, and there are even some residents who have already saved again. The number of accounts opened was 54, out of the targeted 50, there was even 1 person opening deposits ( 1 year term). The total funds raised from this activity amounted to IDR18,333,834, with details of a savings of IDR8,229,000; deposit of IDR10,000,000 and profit sharing of IDR4,834.
\end{abstract}

Keywords: Mother, financial management, savings subsidies, BMT Polidana Polines, saving again

\begin{abstract}
Abstrak
Keluarga merupakan cermin kesejahteraan suatu negara. Bahagia tidaknya suatu keluarga dibebankan pada seorang ibu. Ibu dituntut serba bisa dan serba tahu, tanpa melihat latar belakang keluarga atau darimana ia berasal. Keuangan adalah hal penting untuk menopang pemenuhan kebutuhan primer maupun sekunder. Tidak tersedianya uang saat dibutuhkan dapat memicu permasalahan keluarga, anggota keluarga jadi tertekan. Setiap keluarga/individu selalu berusaha agar kebutuhannya terpenuhi.
\end{abstract}

Kegiatan pengabdian ini bertujuan membantu ibu-ibu mengelola keuangan keluarganya, sehingga dapat tercipta kedamaian keluarga. Pelaksanaan kegiatan didahului dengan sosialisasi kepada para ibu pada saat pertemuan RT, RW, Dawis dan PKB.

Kegiatan diawali paparan pengelolaan keuangan keluarga, prosedur pembukaan simpanan pada BMT Polidana Polines, dilanjutkan sharing tentang masalah keuangan di keluarga, serta pendampingan untuk menambah pemahaman pentingnya pengelolaan keuangan. Motivasi dengan memberikan subsidi Rp 
12.000,- untuk setiap pembukaan rekening (simpanan pokok Rp 10.000,- dan simpanan wajib Rp 2.000,) .

Subsidi dapat menarik warga untuk mulai menabung, bahkan ada sebagian warga yang sudah melakukan menabung ulang. Jumlah rekening yang dibuka ssejumlah 54, dari 50 yang ditargetkan, bahkan ada 1 orang membuka deposito (berjangka 1 th). Total dana yang terhimpun dari kegiatan ini sebesar Rp 18.333.834,, dengan rincian simpanan Rp 8.229.000,-; deposito Rp 10.000.000 dan bagi hasil Rp 4.834,-

Kata kunci : Ibu, pengelolaan keuangan, subsidi simpanan, BMT Polidana Polines, menabung ulang

\section{LATAR BELAKANG MASALAH}

Keluarga adalah unit terkecil dari sebuah bangsa. Masyarakat dalam keluarga yang selalu terpenuhi kebutuhannya akan mengindikasikan makmurnya suatu negara.

Sebagian besar masyarakat berpendapat bahwa berhasil/bahagia tidaknya suatu keluarga terletak di tangan seorang ibu. Seorang ibu dituntut untuk serba tahu berbagai ilmu yang dibutuhkan dalam menjalani hidup berumah tangga, atau dengan kata lain seorang ibu dianggap menguasai berbagai macam seluk beluk kehidupan, dari posisi sebagai juru masak, dokter, ahli di bidang keuangan, sebagai seorang guru di rumah disamping pekerjaan-pekerjan yang lain, sandang dan pangan, sehingga apabila terjadi suatu maslah pasti ibu yang dianggap menjadi penyebabnya, karena tidak pecusnya mengurus keluarga/rumah tangga.

Pendidikan dasar berawal dari keluarga dan itu dibebankan pada ibu. Dalam suatu keluarga seorang ibu merupakan pribadi yang dituntut serba bisa dalam segala hal, tanpa memandang latar belakang pendidikan ataupun status sosial keluarganya.

Pemberdayaan perempuan untuk menopang ekonomi keluarga, merupakan hal yang sangat penting dan sudah tidak asing lagi. Namun demikian di sisi lain ada hal yang tidak kalah pentingnya, yaitu kemampuan dalam pengelolan keuangan yang ada di dalam keluarga, sehingga dapat memenuhi kebutuhan keluarga pada saat diperlukan. Dengan kata lain, bila ingin bahagia keluarganya, maka dana/uang harus selalu tersedia apabila dibutuhkan, hal ini wajib dikuasai oleh seorang ibu dalam memanage/mengatur dan mengelola keuangan dalam keluarga. 


\section{PERMASALAHAN MITRA}

Keterbatasan dana/uang dalam sebuah keluarga tidaklah dapat dipungkiri. Banyak keluarga yang sudah bekerja keras untuk dapat memenuhi berbagai kebutuhannya. Apabila terjadi kekurangan atau kesulitan banyak sekali usaha yaitu dengan bekerja tambahan bahkan bila terpaksa guna mencukupi kebutuhan keuangannya ditasi dengan cara mengambil pinjaman.

Ketersediaan dana dalam keluarga pada saat dibutuhkan, menjadi dambaan setiap keluarga. Sangat diperlukan adanya pemahaman akan pengelolaan keuangan keluarga, sehingga seorang ibu dituntut dapat melakukannya, dengan harapan akan tercipta kedamaian, kebahagiaan dan kesejahteraan dalam keluarga akan selalu terjaga.

Agar hal tersebut dapat dicapai, diperlukan adanya pengarahan serta pendampingan dalam hal pengelolaan keuangan keluarga tersebut.

\section{CARA PEMECAHAN}

Polines melakukan Pengabdian Pada Masyarakat di wilayah Srondol Wetan Banyumanik Semarang menyasar para Ibu rumah tangga. Pihak mitra menyediakan tempat termasuk peserta/ibu-ibu wilayah RW 1 yang terdiri dari 13 RT, sedangkan tim Polines sebagai pelaksana kegiatan, menyediakan tutor/tenaga ahlinya serta prasarana pendukungnya,

Kegiatan ini melibatkan pula personil dari BMT Polidana, yaitu Direktur dan petugas administrasinya.

Yang dilakukan adalah :

a. Lecturing, yaitu transfer pengetahuan pengelolaan keuangan di keluarga

b. Mentoring, dengan memberi contoh langsung pemanfaatan pengelolaan keuangan

c. Focus Group Discussion, berupa adanya sesi tanya jawab

d. Monitoring, dalam hal ini adalah pendampingan secara berkelanjutan termasuk memberikan bantuan demi mendorong dibukanya rekening tabungan di BMT Polidana Polines

e. Evaluasi, yang dilakukan di akhir pertemuan kegiatan 


\section{TAHAP PELAKSANAAN}

Sebelum kegiatan dilaksanakan, diawali dengan hadir pada saat pertemuan ibu-ibu PKK dengan tujuan, memberikan sekilas arahan awal tentang kegiatan yang akan dilaksanakan di waktu yang akan datang.

Pengarahan awal tersebut dimaksudkan untuk memberikan gambaran kepada para ibu akan apa yang akan dilakukan, disamping itu disiapkan juga undangan agar informasi tersebut bisa disampaikan kepada warga yang lain.

Disebabkan oleh berbagai macam keterbatasan, sehingga tidak mungkin mengundang seluruh warga/ibu untuk bisa hadir, maka pada saat pengarahan tersebut diberikan juga formulir pembukaan rekening simpanan. Hal tersebut untuk mengantisipasi apabila ada warga yang ingin ikut buka rekening simpanan tetapi tidak bisa hadir.

Pada saat pelaksanaan yang bertempat di rumah Ibu RW Srondol Wetan Banyumanik, dihadiri oleh warga wakil dari para pengurus PKK RT, juga dihadiri oleh utusan dari P3M Polines.

Setelah acara dibuka dengan doa, selanjutnya diberikan paparan tentang pengelolaan keuangan keluarga dan pengarahan tentang produk BMT Polidana Polines serta mekanisme/prosedurnya.

Sebagai bukti bahwa warga antusias adalah banyaknya pertanyaan dari warga yang hadir sehubungan dengan materi yang diberikan, sehingga terjadi sharing.

Pendampingan terus dilakukan, dengan menghadiri berbagai macam pertemuan pada berbagai kesempatan,misalnya pada pertemuan RT, dawis dan PKB, sehingga banyak warga yang pada akhirnya memutuskan utnuk ikut ambil kesempatan dengan membuka simpanan di BMT Polidana dengan beragam setoran awal, sesuai dengan ketersediaan dana masing-masing.

Kegiatan ini dilakukan di wilayah Srondol Wetan, Banyumanik Semarang. Pihak mitra menyediakan tempat termasuk peserta/ibu-ibu yang merupakan wakil dari masingmasing RT yang berada di dalam RW I, sedangkan tim pengusul sebagai pelaksana 
kegiatan melibatkan pula personil dari BMT Polidana, yaitu Direktur dan petugas administrasinya.

\section{HASIL YANG DICAPAI}

Dalam kegiatan pengabdian kepada masyarakat yang pelaksanaannya diawali dengan tahap pendahuluan, yaitu dalam bentuk sosialisasi tentang akan diadakannya kegiatan tersebut. Hal tersebut dilakukan agar penggunaan waktu lebih efektif Setelah dilakukan berbagai paparan, pengarahan, penjelasan dan pendampingan tentang keuangan keluarga serta pengelolaannya, maka ada beberapa warga yang pada akhirnya timbul minat untuk membuka rekening pada BMT Polidana Polines.

Dalam perjalanan pada faktanya, ada beberapa yang tidak hanya membuka rekening untuk keuangan keluarganya (biaya sekolah, menikah, dll), tetapi juga untuk keuangan organisasi. Hal tersebut dilakukan agar ada pemisahan antara keuangan keluarga \& keuangan organisasi (sebagai bendahara).

Meskipun buku tabungan belum diserahkan kepada nasabah, karena belum berakhirnya masa/periode kegiatan ini, hal tersebut tidak mengurangi minat nasabah untuk menabung ulang, sehingga ada beberapa nasabah yang sudah bertambah jumlah simpanannya serta sudah mendapatkan bagi hasil atas simpanan yang sudah dilakukan tersebut. Bahkan ada juga yang menyimpan uangnya dalam bentuk deposito.

Sampai berakhirnya waktu pelaksanaan kegiatan pengabdian kepada masyarakat ini, ada sekitar 54 nama yang melakukan pembukaan transaksi dan mendapat subsidi Rp 12.000,- karena mereka melakukan pembukaan rekening simpanan umat pada BMT Polidana Polines. Pembukaan simpanan seharusnya dibutuhkan dana sebesar Rp 22.000,-, diberikan subsidi sebesar Rp 12.000,- (Rp 10.000 untuk simpanan Pokok dan Rp 2.000,- untuk simpanan wajib), sedangkan yang Rp 10.000,- dana dari masyarakat sendiri. Hal ini dilakukan agar masyarakat ikut ambil bagian dalam pembukaan simpanan tersebut, sehingga akan menimbulkan keinginan untuk melanjutkan untuk melakukan simpanan yang berulang.

Dengan dilakukannya pendampingan selama kegiatan ini, maka ada beberapa orang yang sudah melakukan transaksi/menabung lebih dari 1 kali, bahkan ada yang sudah 4 kali, sehingga mereka menikmati bagi hasil yang lebih dari yang lain. 
Belum diterimakannya buku tabungan kepada mereka bukan merupakan penghambat bagi sekian orang utntuk terus melakukan transaksi.

Dampak dari kegiatan pendampingan ini adalah terserapnya dana dari masyarakat yang jumlahnya lebih dari 18 juta.

Sampai berakhirnya kegiatan ini jumlah simpanan Rp 18. 333.834,- (delapan belas juta tiga ratus tiga puluh tiga ribu delapan ratus tiga puluh empat rupiah) termasuk di dalamnya simpanan berjangka/deposito dengan jangka waktu 1 tahun senilai Rp 10.000.000,- dan bagi hasil dengan rincian :

DAFTAR PENERIMA BANTUAN/SUBSIDI \& JUMLAH SIMPANAN PADA BMT POLIDANA POLINES posisi pada tanggal 13 September 2019

\begin{tabular}{|c|c|c|c|c|c|c|c|}
\hline \multirow{2}{*}{ NO } & \multirow{2}{*}{ NAMA } & \multicolumn{4}{|c|}{ Simpanan (ribuan rupiah) } & \multicolumn{2}{|c|}{ Bagi Hasil (Rp) } \\
\hline & & 1 & 2 & 3 & 4 & 1 & 2 \\
\hline 1 & Agustin Dwi A & 50 & & & & 15 & \\
\hline 2 & Aida Farzanah & 50 & & & & & \\
\hline 3 & Amirotus S & 10 & & & & & \\
\hline 4 & Bambang $\mathrm{S}$ & 50 & & & & & \\
\hline 5 & Berliana K & 20 & & & & & \\
\hline 6 & Bidayatun $\mathrm{N}$ & 10 & 50 & & & 4 & \\
\hline 7 & Christi Mega D & 20 & & & & 8 & \\
\hline 8 & Desi Atika $S$ & 10 & & & & & \\
\hline 9 & Destriana & 20 & & & & & \\
\hline 10 & Djumiati & 50 & & & & 15 & \\
\hline 11 & E. Sri Sulistyantini & 50 & & & & & \\
\hline 12 & Evy Dwi Y & 100 & & & & & \\
\hline 13 & Frizka F & 10 & & & & & \\
\hline 14 & Giyarni & 50 & 100 & & & 39 & 56 \\
\hline 15 & Heni $S$ & 10 & & & & & \\
\hline 16 & Henry Pangku Winatun & 50 & 50 & & & 27 & 105 \\
\hline 17 & Indah Prihatin & 50 & & & & & \\
\hline 18 & Indhira & 50 & & & & & \\
\hline 19 & Indrawati & 50 & & & & 47 & \\
\hline 20 & Jumirah & 50 & 100 & & & 21 & \\
\hline 21 & Kartika Sindy S & 20 & & & & & \\
\hline 22 & Lasiyem & 150 & 100 & 100 & & 122 & 269 \\
\hline 23 & Lely Ajeng & 30 & & & & & \\
\hline 24 & Maria Agustin K & 50 & & & & 39 & 58 \\
\hline 25 & Muhammad Fariz Nf & 10 & & & & & \\
\hline
\end{tabular}




\begin{tabular}{|c|c|c|c|c|c|c|c|}
\hline 26 & Mur Wahyunani & 10 & 15 & & & 9 & \\
\hline 27 & Niovita Anggraeni & 100 & & & & & \\
\hline 28 & Nisrina Marchy M & 10 & & & & & \\
\hline 29 & Nugroho Heri P & 12 & & & & 1 & \\
\hline 30 & Nur Hidayat & 10 & & & & & \\
\hline 31 & Oktaviana Indri & 100 & & & & & \\
\hline 32 & Prihatin & 50 & 100 & 100 & & 99 & 206 \\
\hline 33 & Prihatin - Kel Tani & 3.845 & & & & 2.166 & \\
\hline 34 & Prihatin-2 & 10 & & & & 6 & \\
\hline 35 & Puspita Dwi & 100 & & & & & \\
\hline 36 & Rianto & 50 & 100 & & & 15 & \\
\hline 37 & Rijati & 22 & & & & & \\
\hline 38 & Rikanah & 200 & 100 & 100 & 100 & 109 & 282 \\
\hline 39 & Sri Maryatun & 50 & 100 & & & 41 & 88 \\
\hline 40 & Srijatun & 50 & 50 & & & 41 & 105 \\
\hline 41 & Suarti & 10 & 50 & 50 & 50 & 37 & 117 \\
\hline 42 & Sudewi Narti & 10 & 50 & & & 8 & 12 \\
\hline 43 & Sulistyo Anggoro & 10 & 200 & 200 & & 6 & 139 \\
\hline 44 & Sumiyati & 50 & 50 & 50 & & 27 & 105 \\
\hline 45 & Sunarni & 50 & & & & 41 & 58 \\
\hline 46 & Suyanti & 20 & 50 & & & 10 & 10 \\
\hline 47 & Swadhesi & 100 & & & & & \\
\hline 48 & Tia Herawati & 20 & & & & & \\
\hline 49 & Tjpta Muliani & 10 & & & & & \\
\hline 50 & Triana MM & 10 & & & & & \\
\hline 51 & Tuti Yuliah & 10 & 10 & & & 8 & 21 \\
\hline 52 & Umi Kalsum & 50 & 100 & & & 29 & 152 \\
\hline 53 & Visara Virda L & 15 & & & & & \\
\hline 54 & Wahyuni & 30 & 50 & 20 & & 17 & 44 \\
\hline & Jumlah & 6.034 & 1.425 & 620 & 150 & 3.007 & 1.827 \\
\hline & Jumlah Simpanan & \multicolumn{4}{|c|}{8.229 (ribuan rupiah) } & & \\
\hline & Jumlah Bagi Hasil & & & & & 4.834 & \\
\hline 55 & Prihatin (Deposito - 1 th) & \multicolumn{4}{|c|}{10.000 (ribuan rupiah) } & & \\
\hline & $\begin{array}{c}\text { Jumlah Simpanan. \& } \\
\text { Bagi Hasil }\end{array}$ & \multicolumn{6}{|c|}{ 18.333.834 } \\
\hline
\end{tabular}



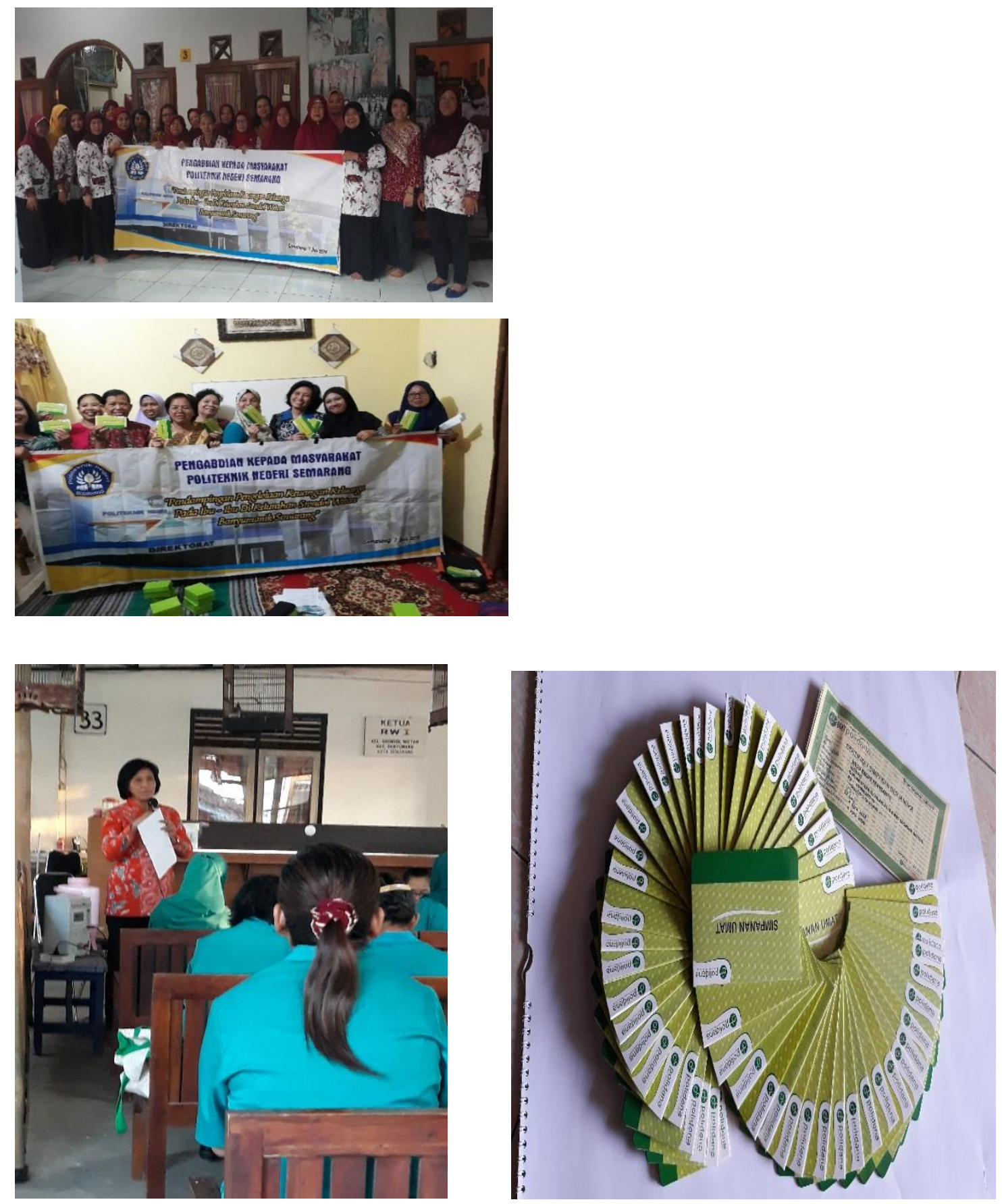

\section{KENDALA DAN SOLUSI}

Kendala yang ada :

a. Sulitnya menyamakan waktu pelaksanaan antara tim pelaksana dengan warga yang jumlahnya tidak sedikit dengan berbagai macam kesibukan yang dimiliki 
b. Terbatasnya waktu pelaksanaanyang tersedia, sehingga warga merasa kurang puas

c. Adanya pengalaman yang tidak/kurang menyenangkan yang pernah dialami oleh warga dalam hal simpanan yang ada di bank

Solusi yang dilakukan antara lain :

a. Adanya komitmen bersama demi terlaksananya kegiatan dengan sukses

b. Pembagian tugas, sehingga dapat memaksimalkan dan mengefektifkan penggunaan waktu waktu yang ada

c. Adanya upaya yang lebih untuk bisa memberikan gambaran/pemahaman kepada warga serta memberikan memotivasi/meyakinkan keputusan untuk menabung demi masa depan.

\section{KESIMPULAN}

Kesimpulan yang bisa diambil pengabdian kepada masyarakat ini adalah diperlukannya kontinyuitas pemberian pemahaman tentang pentingnya pengelolaan keuangan keluarga, agar keharmonisan/perdamaian dan kebahagiaan seluruh anggota di dalam keluarga dapat terjamin. Hal ini dikarenakan keuangan keluarga merupakan faktor yang sangat sering terjadi menjadi pemicu keributan dalam keluarga.

Dengan intensifnya pemberian pemahaman dan pendampingan akan dapat mengubah pengertian/pemahaman/kesadaran pada masyarakat mengelola keuangan keluarga.

Dengan terkelolanya keuangan keluarga diharapkan akan dapat berdampak pada terciptanya kebahagiaan dalam keluarga, yang pada akhirnya akan berdampak pada stabilnya bidang keuangan suatu negara. Hal tersebut terjadi dikarenakan unsur yang terkecil suatu negara adalah keluarga.

\section{SARAN}

Berdasarkan kesimpulan yang diambil, maka kegiatan pengabdian kepada masyarakat ini dapat memberikan saran agar: 
a. Untuk di masa yang akan datang dapat dilakukan hal yang sama di daerah yang berbeda, agar manfaat dan info akan keberadaan BMT Polidana yang berada di Politeknik Negeri Semarang bisa lebih maksimal dan optimal, sehingga keberadaan lembaga dapat dirasakan oleh masyarakat yang lebih luas.

b. Disamping itu juga bisa dilakukan untuk materi pemahaman yang lain, tentang kesenjangan yang ada di masyarakat.

\section{DAFTAR PUSTAKA}

Kotler.2006.Marketing Management.Pearson Education Limited.England

Pearce dan Robinson. (1997). Manajemen Strategik. (terjemahan Agus Maulana). Jakarta : Binarupa Aksara.

Widowati, Mustika, 2003. Laporan Penelitian Peran PKK Dalam Pemberdayaan Wanita di Indonesia, Semarang.

$$
* * * * *
$$

